\title{
Kajian Fasies Gunungapi di Kompleks Candi Asu untuk Pendugaan Bencana Erupsi Merapi
}

\author{
ARIF ASHARI \\ Jurusan Pendidikan Geografi FIS UNY \\ e-mail : ariecarstensz@gmail.com
}

\begin{abstract}
Abstrak
Penelitian ini bertujuan mengkaji fasies gunung api dan jenis bahaya erupsi yang pernah terjadi di sekitar kompleks Candi Asu. Metode yang digunakan adalah eksploratif-survey. Pengumpulan data dengan observasi, studi pustaka, dan dokumentasi. Data yang dikumpulkan berupa primer dan sekunder. Data primer meliputi jenis batuan, kemiringan lereng, dan arah lereng dari pengukuran lapangan, dengan penentuan lokasi sampel menggunakan metode sistematik sampling. Data sekunder meliputi kondisi topografi dan geologi dari interpretasi peta rupabumi indonesia, peta geologi, dan citra ikonos pada google earth. Analisis dilakukan secara deskriptif memperhatikan aspek keruangan. Hasil penelitian menunjukkan kompleks Candi Asu termasuk fasies medial yang dikenali berdasarkan analisis geomorfologi dan litofasies. Secara geomorfologi berada pada satuan bentuk lahan kaki gunung api dengan litofasies endapan tuf, lahar, dan piroklastik. Pada masa lampau kompleks Candi Asu mengalami bencana akibat aliran lahar, awan panas, dan hujan abu menyebabkan beberapa candi terkubur material vulkanik.
\end{abstract}

Kata kunci: gunungapi, fasies gunungapi, erupsi, geomorfologi

\begin{abstract}
This research aims to investigate the volcanic facies and types of eruption danger that had ever happened around the complex of Asu temple. The method used in this research is exploratory - survey. Data was collected through observation, library research, and documentation. The data were categorized into primary and secondary data. Primary data include rock type, slope, and the slope obtained from field measurements, the determination of the location of the sample using a systematic sampling method. The secondary data include topographical and geological conditions obtained from the interpretation of Indonesian topographic maps, geological maps and IKONOS imagery on google earth. The analysis was performed descriptively by taking into account spatial aspects. The results show that Asu temple complex including the medial facies were identified based on the analysis of geomorphology and litofasies. In reference to geomorphology, this region is located at the foot of volcanic land form unit with a sediment litofasies tuff, lava, and pyroclastic. In the past, Asu temple complex had ever experienced a disaster due to the flow of lava, heat clouds and ash rain that caused some temples buried by volcanic material.
\end{abstract}

Keywords: volcanic facies, volcanic eruption, geomorphology 


\section{PENDAHULUAN}

Wilayah lereng barat Gunungapi Merapi telah sejak lama ditempati oleh penduduk. Keberadaan kompleks Candi Asu di sempadan Sungai Pabelan menunjukkan di wilayah tersebut telah berlangsung penghunian oleh masyarakat disertai dengan berkembangnya kebudayaan sejak masa Hindu-Buddha. Kompleks Candi Asu berada pada lahan seluas 2,55 ha, terdiri dari tiga candi yaitu Candi Asu, Candi Lumbung, dan Candi Pendem. Ketiga candi tersebut dibangun pada periode 830-900 M (Degroot, 2009: 12-15). Pemilihan lokasi permukiman dan pembangunan candi pada lereng vulkan diduga kuat tidak terlepas dari keberadaanpotensi sumberdaya alam wilayah tersebut. Selama ini lereng Gunungapi Merapi diketahui banyak memiliki potensi sumberdaya alam berupa sumberdaya air (Santosa, 2006: 1; Sutikno dkk, 2007: 39-51), sumberdaya lahan, sumberdaya mineral, dan sumberdaya hayati (Sutikno dkk, 2007: 51-61).

Namun demikian, disamping potensi sumberdaya alam Gunungapi Merapi juga menyimpan potensi bencana yang cukup besar (Sutikno dkk, 2007: 20-30). Gunungapi Merapi dikenal sebagai salah satu vulkan paling aktif di Indonesia, bahkan oleh Sudradjat dkk (2011) disebut sebagai vulkan paling aktif selama Holosen dengan aktivitas yang berkesinambungan. Oleh karena itu kehidupan penduduk pada lereng Merapi sepanjang waktu senantiasa menghadapi ancaman bencana akibat aktivitas vulkanisme. Terlebih pada masa lalu daerah yang banyak mengalami dampak langsung letusan adalah lereng barat atau barat daya (Andreastuti dkk, 2006: 2) yang telah menjadi pusat-pusat konsentrasi penduduk dengan peninggalan berupa candi yang dijumpai saat ini.

Selama ini banyak diyakini aktivitas vulkanik Merapi merupakan salah satu faktor yang menyebabkan kemunduran periode Hindu-Buddha di Jawa Tengah, dalam konteks ini khususnya wilayah kompleks Candi Asu yang berada pada lereng barat Merapi. Bencana alam akibat letusan Merapi sejak awal abad ke 11 telah banyak menyebabkan gangguan kehidupan (Sutikno dkk, 2007: 1920) sehingga mendorong perpindahan pusat kekuasaan ke Jawa Timur, dan oleh karena perpindahan tersebut Jawa Tengah tidak lagi memiliki pengaruh besar hingga beberapa abad kemudian pada masa perkembangan Islam (Degroot, 2009: 8). Mencermati dampak bencana Erupsi Gunungapi Merapi sejak masa lampau, menarik untuk dikaji bahayabahaya apa saja yang pernah terjadisehingga melumpuhkan sistem kehidupan masyarakat di kompleks Candi Asu. Kajian mengenai bencana pada masa lampau diharapkan dapat meningkatkan kewaspadaan dan kesiapsiagaan masyarakat pada saat ini mengingat wilayah tersebut saat ini ditempati oleh penduduk dengan jumlah dan kepadatan tinggi.

Kajian fasies gunungapi berperan sebagai penyedia catatan sejarah erupsi pada masa lampau, untuk pengenalan dan pemahaman sifat erupsi yang terjadi pada suatu tempat sehingga dapat diprediksi dampak erupsi pada masa mendatang (Marfai dkk, 2012: 3). Fasies gunungapi merupakan sejumlah ciri litologi batuan gunungapi dalam kesamaan waktu pada suatu lokasi tertentu yang menyangkut aspek fisika, kimia, biologi (Bronto, 2006: 2). Analisis fasies gunungapi menganggap bahwa setiap proses yang terjadi saat erupsi akan menghasilkan jenis batuan yang berbeda sehingga dengan mengidentifikasi batuan tersebut akan diketahui jenis bahaya erupsi yang pernah terjadi pada suatu tempat (Marfai dkk, 2006: 3). Oleh karena itu kajian fasies gunungapi merupakan salah satu metode yang dapat digunakan untuk rekonstruksi bencana erupsi masa lalu sekaligus prediksi bencana masa mendatang di wilayah kompleks Candi Asu.

Dalam geomorfologi terdapat konsep dasar yang menyatakan: "hukum dan proses fisis yang berlaku pada saat ini, berlangsung pula sepanjang waktu geologi walaupun intensitasnya tidak selalu sama dengan saat ini" (Thornbury, 1969: 16 ). Konsep ini menunjukkan proses alami yang terjadi di masa lalu sangat mungkin untuk terjadi kembali di masa depan. Dengan demikian bahaya erupsi yang pernah terjadi di wilayah kompleks Candi Asu pada masa lalu pada hakikat- 
nya masih merupakan ancaman bagi periode sekarang maupun yang akan datang. Berkaitan dengan hal tersebut kajian fasies gunungapi sangat penting karena dengan merekonstruksi peristiwa yang telah terjadi di masa lalu dapat diperoleh gambaranpotensi bencana yang masih menjadi ancaman di masa mendatang. Informasi potensi bencana sangat dibutuhkan dalam membangun sistem kehidupan masyarakat yang selaras dengan becana (Kelman dan Mather, 2008: 2-3)

\section{METODE}

Penelitian ini menggunakan metode eksploratif-survei dengan pendekatan keruangan dan kelingkungan. Survei geomorfologi digunakan dengan memperhatikan aspek morfologi dan morfogenesa. Populasi dalam penelitian ini meliputi seluruh lahan di kompleks Candi Asu dengan pengambilan sampel secara sistematik random sampling. Peng- umpulan data dilakukan dengan observasi, interpretasi citra penginderaan jauh, studi pustaka, dan dokumentasi.

Menurut Bronto (2006: 3), fasies gunungapi dapat diidentifikasi berdasarkan data: 1) inderaja dan geomorfologi, (2) stratigrafi batuan gunungapi, 3) vulkanologi fisik, 4) struktur geologi, dan 5) petrologi-geokimia. Penelitian ini melakukan identifikasi fasies dengan kombinasi cara pertama dan kedua, yaitu antara inderaja dan geomorfologi dengan stratigrafi batuan gunungapi. Untuk itu data yang dikumpulkan meliputi data morfologi dan data litofasies sebagai data primer yang diperoleh dari pengukuran lapangan, dengan didukung data sekunder berupa kondisi geologi dan geomorfologi regional yang diperoleh dari interpretasi peta rupabumi indonesia, peta geologi, citra landsat dan citra ikonos pada google earth, serta sumber-sumber pustaka. Jenis data dan metode pengumpulannya ditunjukkan pada Tabel 1.

Tabel 1. Jenis data dan teknik pengumpulan data

\begin{tabular}{ccc}
\hline Jenis data & $\begin{array}{c}\text { Teknik pengumpulan } \\
\text { data }\end{array}$ & Instrumen/sumber data \\
\hline
\end{tabular}

Variabel morfologi

1. Bentuklahan

2. Kemiringan lereng

3. Hadap lereng

4. Genesis dan proses

Variabel litofasies

1. Tipe produk erupsi

2. Stratigrafi endapan Gunungapi Merapi
Observasi

Interpretasi citra

Studi pustaka

Observasi

Dokumentasi

Observasi

Observasi

Observasi

Dokumentasi

Studi pustaka
Lembar observasi, kamera

Citra landsat dan ikonos yang tersedia pada google earth

Sutikno dkk (2006)

Klinometer, yallon

Peta RBI dan DEM SRTM

Kompas, yallon

Lembar observasi, kamera

Lembar observasi, kamera

Peta Geologi

Andreastuti dkk (2006) 
Data yang diperoleh selanjutnya dianalisis secara deskriptif. Identifikasi fasies dengan analisis aspek geomorfologi dilakukan melalui pencocokan (matching) antara kon- disi morfologi di lapangan dengan ciri-ciri morfologi pada setiap fasies sebagaimana dijelaskan oleh Bronto (2006: 3-4).

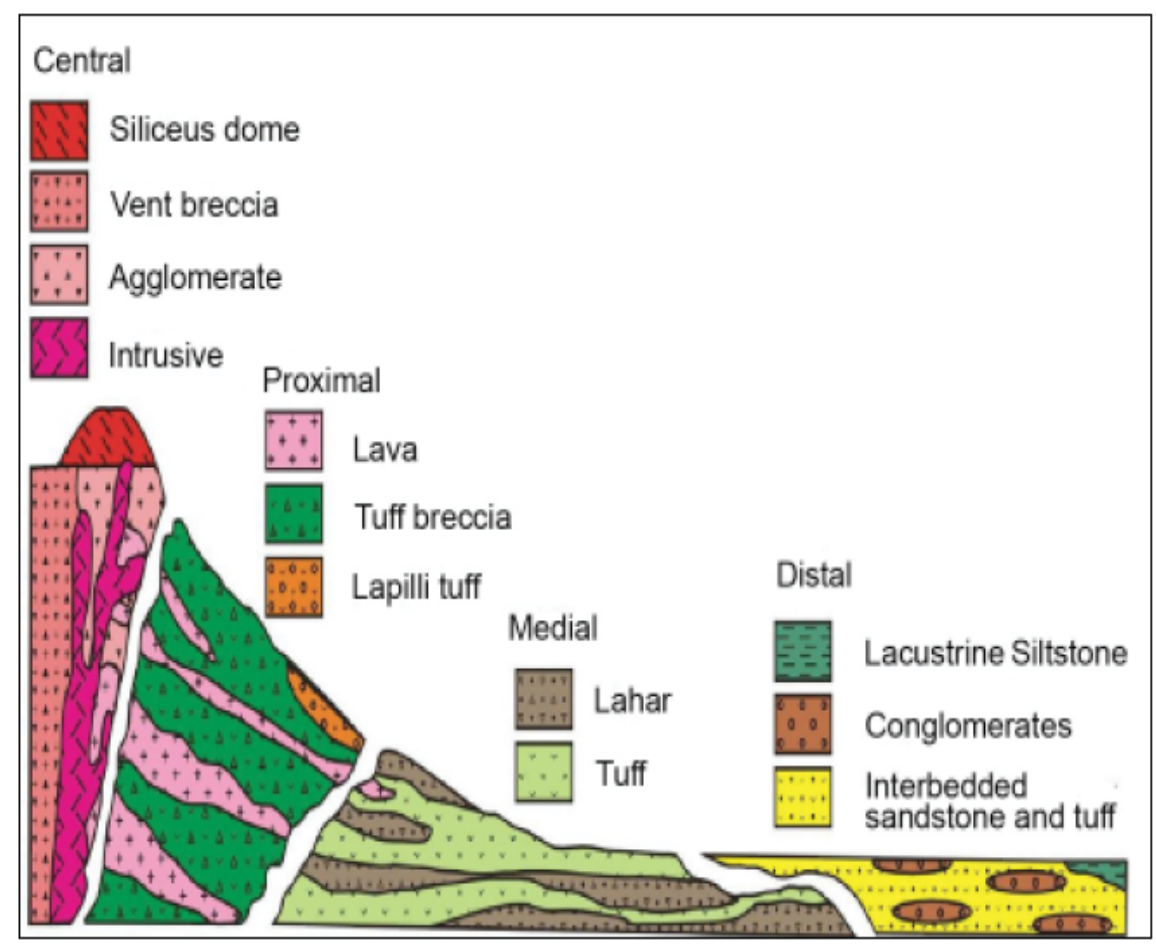

Gambar 1.

Klasifikasi fasies gunungapi beserta komposisi batuan penyusunnya (Bogie dan Mackenzie, 1998 dalam Bronto, 2006: 3)

\section{HASIL DAN PEMBAHASAN}

Daerah penelitian terletak pada koordinat 429060 hingga 429190 serta 9167870 hingga 9167950 pada zona 49 UTM. Luas wilayah 2,5 ha, secara administrasi sebagian besar termasuk dalam wilayah Desa Sengi, Kecamatan Dukun, serta sedikit bagian termasuk dalam wilayah Desa Krogowanan Kecamatan Sawangan, Kabupaten Magelang (Gambar 2).

Keseluruhan wilayah berada pada sempadan Sungai Pabelan dengan jarak terjauh dari lembah sungai 110 meter.Secara geologi keseluruhan wilayah termasuk dalam Endapan Gunungapi Merapi Muda (Qmi) dengan litologi tuf, abu, breksi, aglomerat, dan leleran lava, terletak berbatasan dengan Endapan Gunungapi Merbabu (Qme). Penggunaan la- han berupa tegalan dan permukiman.

Secara geomorfologi, daerah penelitian berada pada bentuk lahan kaki Gunungapi Merapi (volcanic foot)bagian barat. Bentuk lahan ini di bagian atas berbatasan dengan bentuklahan lereng gunungapi (volcanic slope) dan di bagian bawah berbatasan dengan dataran kaki (volcanic foot plain). Masingmasing bentuklahan tersebut dibatasi oleh tekuk-tekuk lereng (break of slope). Sutikno dkk (2007: 17) menjelaskan ciri-ciri bentuklahan kaki Gunungapi Merapi berupa bagian bawah dari tubuh gunungapi di bawah lereng gunungapi yang ditandai perubahan kemiringan lereng dan relief dari semula berbukit pada lereng gunungapi menjadi bergelombang pada kaki gunungapi (Gambar 3). 


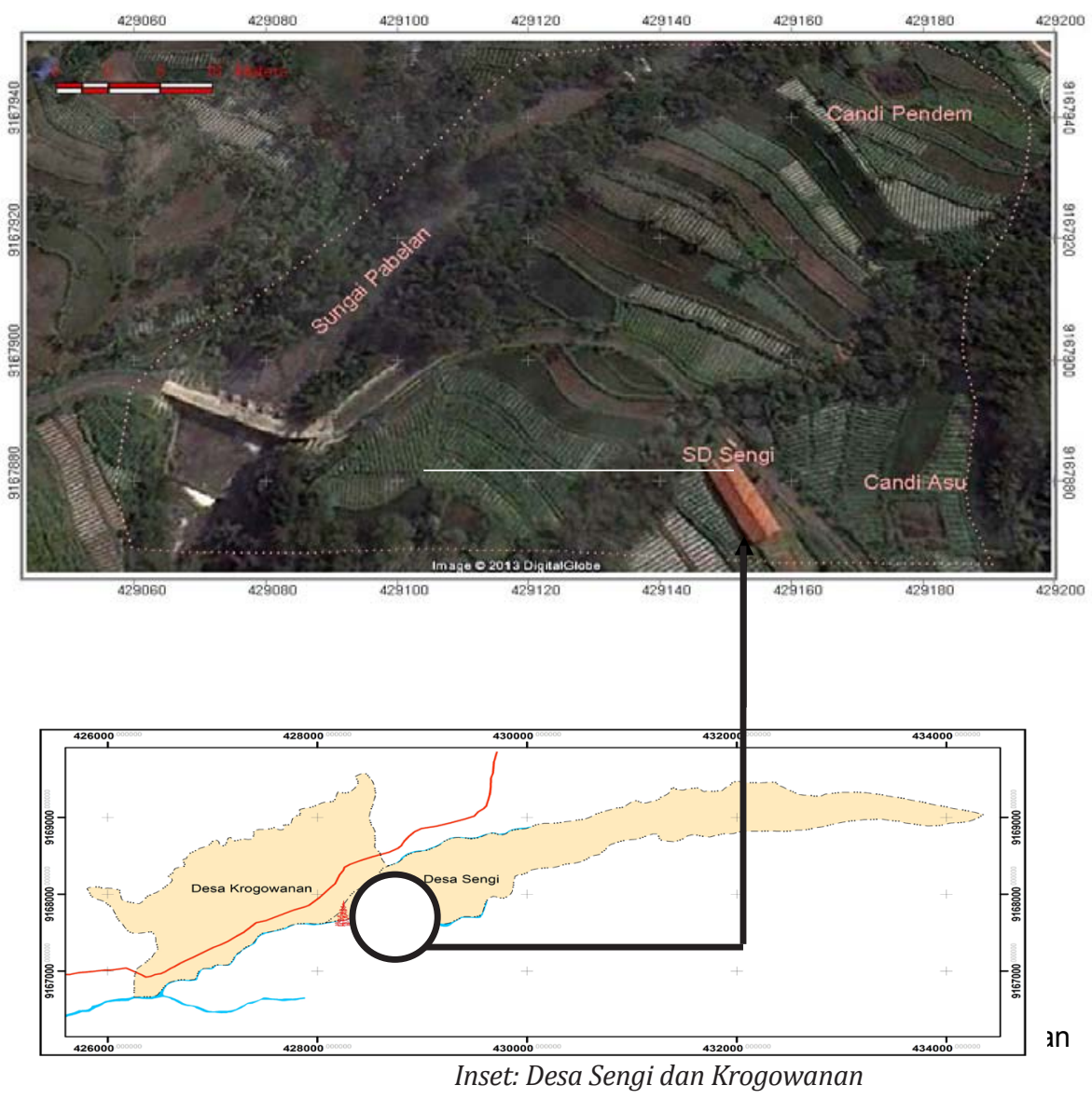

Gambar 2. Daerah penelitian pada citra satelit google earth

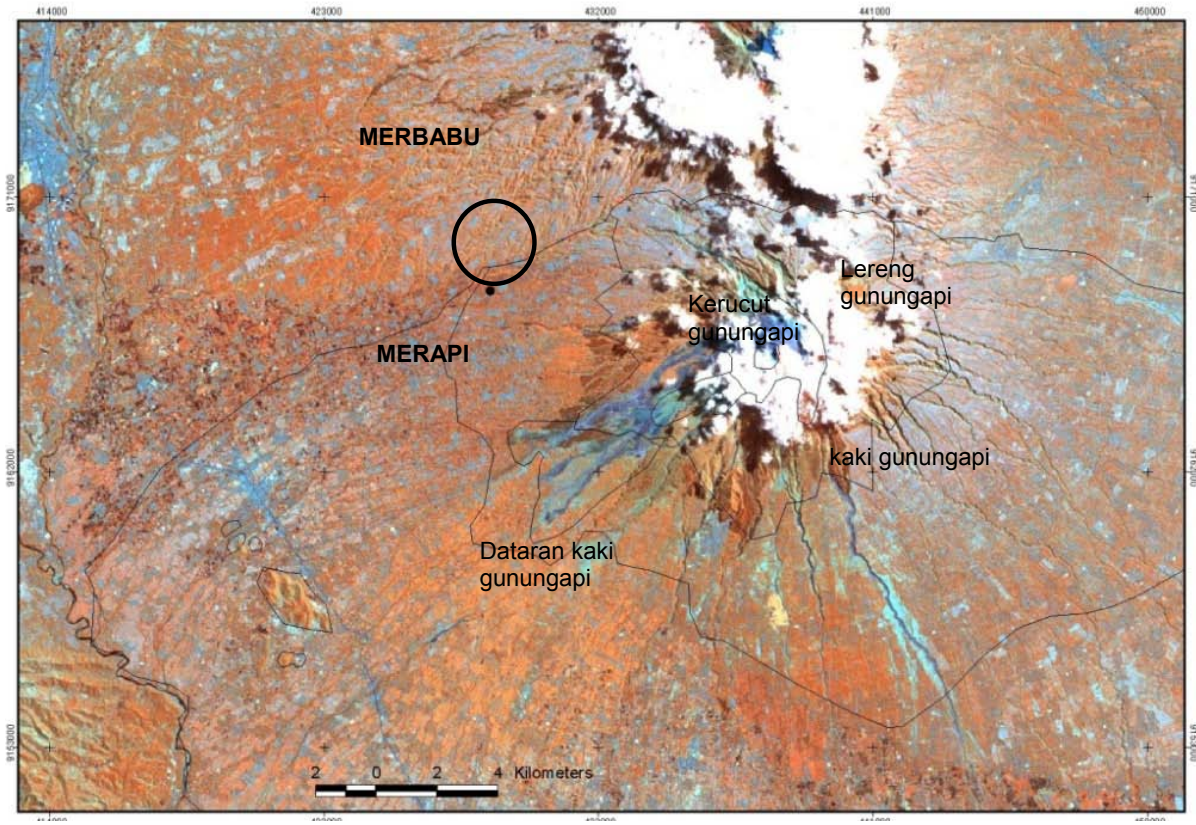

Gambar 3. Kedudukan Daerah Penelitian dalam Pembagian Wilayah Geomorfologi Gunungapi Merapi 
Proses geomorfologi yang berlangsung didominasi oleh proses eksogen yaitu berupa pengendapan material vulkanik yang bersumber dari kepundan. Material vulkanik yang dimaksud berupa piroklastik maupun lahar hasil rombakan kembali endapan pada bentuklahan di bagian atasnya. Proses lainnya yang juga berlangsung adalah pelapu- kan, erosi, dan di beberapa tempat dijumpai gerakan massa. Kemiringan lereng rata-rata berdasarkan pengukuran di beberapa titik sampel adalah 12-15\%, dengan hadap lereng ke arah barat-barat daya. Rangkuman kondisi geomorfologi di daerah penelitian ditunjukkan oleh Tabel 2.

Tabel 2. Kondisi Geomorfologi Daerah Penelitian

\begin{tabular}{ll}
\hline Bentuklahan & Kaki Gunungapi \\
Kemiringan lereng & $12-15 \%$ \\
Relief & Bergelombang \\
Batuan dan struktur & Endapan piroklastik dan aluvial \\
Proses & $\begin{array}{l}\text { Pengendapan material piroklastik, pelapukan, gerakan } \\
\text { massa, erosi }\end{array}$ \\
Ciri-ciri & Bagian bawah tubuh gunungapi di bawah lereng \\
& gunungapi, ditandai perubahan kemiringan lereng dari \\
& agak terjal menjadi miring dan relief dari berbukit menjadi \\
& bergelombang
\end{tabular}

Sumber: Survei lapangan (2013); Sutikno dkk (2007)

Sisi barat Gunungapi Merapi termasuk dalam bagian paling muda, yang masih terus terkena dampak langsung peristiwa erupsi berupa pengendapan material-material vulkanik hingga saat ini. Pengendapan material vulkanik tersebut menghasilkan kenampakan khas berupa segmen-segmen bentuklahan yang dibatasi oleh tekuk-tekuk lereng. Bronto (2006: 3) menjelaskan, pada gunungapi muda dengan usia kuarter hingga saat ini bentangalam gunungapi komposit sangat mudah diidentifikasi.Karakteristik utamaberbentuk kerucut yang dapat mudah dipisahkan antara bagian puncak, lereng, kaki, dan dataran di sekitarnya, oleh karena sudut lereng yang semakin melandai. Kedudukan masing-masing segmen dalam tubuh gunungapi inilah yang digunakan sebagai dasar penentuan fasies gunungapi secara geomorfologi.

Bogie dan Mackenzie (1998, dalam Bronto, 2006: 3) membedakan fasies gunungapi menjadi fasies sentral, fasies piroksimal, fasies medial, dan fasies distal. Kompleks Candi Asu yang berada pada bentuklahan kaki gunungapi termasuk dalam fasies medial. Se- bagian kecil wilayah termasuk dalam peralihan antara fasies medial dengan fasies distal, yaitu pada bagian bawah yang berada dekat satuan bentuklahan dataran kaki gunungapi.

Identifikasi fasies gunungapi berdasarkan inderaja dan geomorfologi sebagaimana telah dilakukan di atas, didukung oleh pengamatan litofasies di lapangan. Berdasarkan pengamatan pada beberapa lokasi sampel diketahui wilayah Kompleks Candi Asu didominasi material tuf. Material ini dijumpai pada lahan di sekitar candi yang pada saat ini dimanfaatkan untuk tegalan. Di beberapa tempat material tuf mencapai ketebalan lebih dari dua meter antara lain di Candi Pendem. Sesuai dengan namanya, candi ini pernah terkubur oleh material vulkanik dan ditemukan kembali setelah penggalian. Hal ini nampak jelas dari kedudukan candi yang terletak lebih rendah dari lahan di sekitarnya (Gambar 4).

Material vulkanik lain yang terdapat di daerah penelitian dan berkarakter material fasies medial adalah endapan piroklastik dan lahar. Jenis material ini dijumpai pada lem- 
bah Sungai Pabelan. Pada tebing sungai terdapat lapisan endapan lahar dan piroklastik hingga ketebalan lebih dari tiga meter. Endapan lahar nampak jelas berdasarkan karakteristiknya yaitu memiliki sortasi buruk, ukuran butir bervariasi, beberapa diantaranya memiliki diameter lebih dari 1 meter, serta butiran-butiran tersebut bersisi membulat. Endapan lahar mendominasi lembah Sungai Pabelan (Gambar 5).

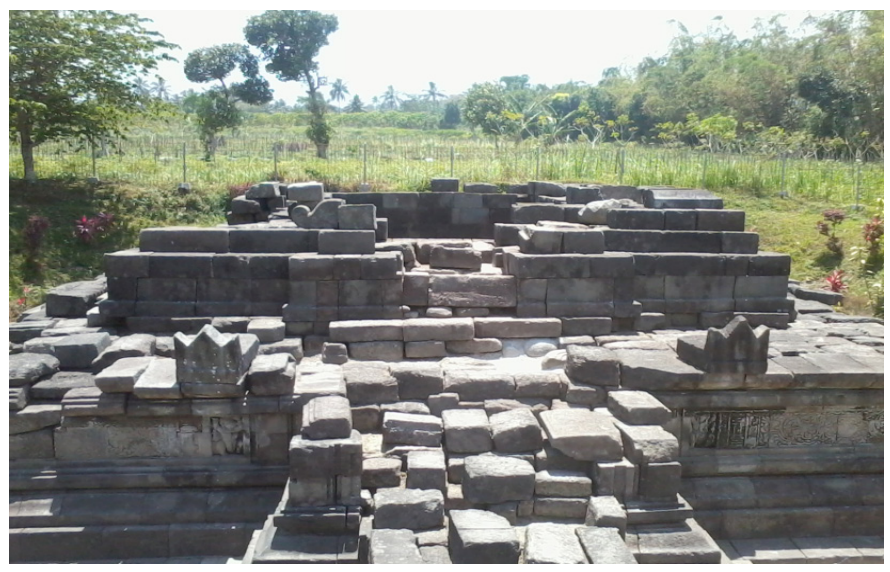

\section{Gambar 4. Candi Pendem yang terletak lebih rendah dari lahan di sekitarnya (lokasi 429484 MT, $9168078 \mathrm{MU}$ )}

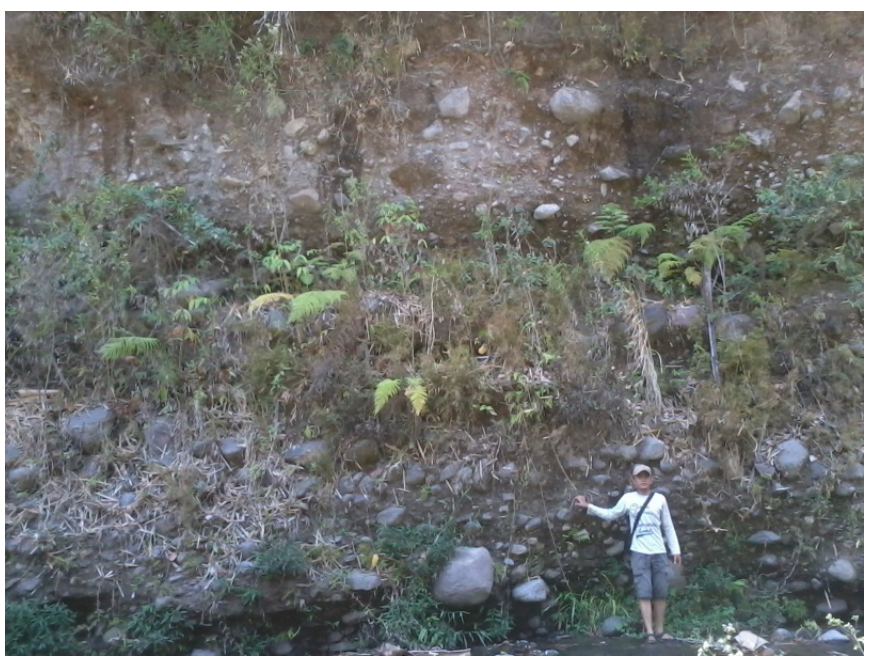

Gambar 5. Pola perlapisan endapan lahar dan piroklastik pada tebing Sungai Pabelan (Lokasi: 428405 MT, 9168074)
Adapun endapan piroklastik cenderung lebih sedikit dengan karakteristik butiran bersisi tajam dan ukuran butir lebih kecil. Keberadaan material tuf serta endapan lahar dan piroklastik daerah penelitian menunjukkan wilayah kompleks Candi Asu pada masa lalu pernah menghadapi bahaya erupsi berupa aliran lahar, awan panas, dan jatuhan abu vulkanik. Aliran lahar dan awan panas terutama terjadi melalui lembah Sungai Pabelan yang berperan sebagai jalur aliran material erupsi dan terhubung langsung dengan pusat aktivitas vulkanik.

\section{HASIL DAN PEMBAHASAN}

Hasil penelitian menggunakan metode analisis inderaja dan geomorfologi dengan didukung pengamatan litofasies di lapangan menunjukkan secara umum wilayah Kompleks Candi Asu termasuk dalam fasies medial.Beberapa bagian yang terletak ke arah hilir menunjukkan transisi fasies medial ke fasies distal. Menurut Bronto (2006: 4) fasies medial cenderung dijumpai pada lereng bawah gunungapi, sedangkan satuan morfologi kaki gunungapi termasuk dalam fasies distal bersama dengan dataran fluvial gunungapi. Namun demikian berdasarkan analisis daerah penelitian yang berada pada kaki gunungapi sebagian besar menunjukkan karakter fasies medial. Hal ini diduga oleh karena kedudukan satuan morfologi kaki gunungapi di daerah penelitian relatif dekat dengan lereng bawah gunungapi serta pengaruh kondisi morfologi regional yang berada pada titik pertemuan kaki Gunungapi Merapi dan Merbabu.

Mencermati pembagian fasies gunungapi oleh Bogie dan Mackenzie (1998 dalam Bronto, 2006: 3), satuan morfologi kaki gunungapi yang berdekatan dengan lereng bawah gunungapi termasuk dalam fasies distal. Namun demikian penelitian ini menunjukkan kemungkinan masih dijumpai karakteristik fasies medial pada wilayah peralihan antara lereng bawah gunungapi dengan kaki gunungapi, sebagaimana yang dijumpai di wilayah sekitar Candi Asu. Hal ini diduga berkaitan dengan proses erupsi besar pada masa lampau yang mengendapkan material penciri fasies medial di wilayah ini yang pada saat 
ini telah mulai dibongkar oleh proses erosi. Pada dasarnya fasies gunungapi dapat segera dikenali dari karakteristik morfologinya terutama pada gunungapi berusia Kuarter karena bentuknya yang berupa kerucut dengan tekuk-tekuk lereng membatasi masingmasing segmen wilayah (Bronto, 2006: 61).
Gunungapi Merapi merupakan kerucut muda berusia kuarter khususnya di wilayah lereng barat daya hingga barat sehingga memudahkan analisis fasies berdasarkan identifikasi morfologi. Kedudukan Candi Asu pada satuan morfologi Gunungapi Merapi ditunjukkan oleh Gambar 6.



Gambar 6.

\section{Pembagian sistem fasies lereng barat Gunungapi Merapi berdasarkan morfologi yang nampak pada citra Google Earth}

Material endapan lahar, endapan piroklastik, dan tuf yang mendominasi kompleks Candi Asu juga mencirikan fasies medial. Bronto (2006: 5) menjelaskan material tuf dan breksi piroklastika merupakan material yang sangat dominan dijumpai pada fasies medial. Selain itu pada fasies medial breksi lahar juga sudah mulai berkembang. Endapan lahar sebagai penciri fasies medial dijumpai pada tebing-tebing sungai yang memiliki lembah yang dalam (Marfai dkk, 2012: 5), sebagaimana dijumpai di lembah Sungai Pabelan dengan ketebalan mencapai tiga meter. Material jatuhan, endapan lahar, dan piroklastik menurut pendapat Davidson dan De Silva (2000: 17) dijumpai pada peralihan antara bagian bawah cone building dengan ring plain, yang kurang lebih sama dengan fasies medial. Dalam kasus daerah dengan morfologi regional berada pada titik pertemuan kaki dua gunungapi seperti di daerah penelitian, ring plain tidak berupa dataran yang ideal tetapi dijumpai dalam bentuk pengendapan material baru pada lembah-lembah sungai. Di lembah Sungai Pabelan terjadi pengendapan material erupsi yang ditandai oleh aliran sungai terpecah dan tidak ada singkapan batuan.

Analisis fasies gunungapi menunjukkan kompleks Candi Asu yang dibangun pada kaki bagian barat Gunungapi Merapi dari waktu ke waktu senantiasa menghadapi ancaman ba- 
haya akibat erupsi gunungapi, dalam hal ini berupa aliran lahar, awan panas, dan material jatuhan dalam bentuk hujan abu maupun lapili. Sejak dibangun pada periode 830-900 M (Degroot, 2009: 12-15), kompleks Candi Asu banyak menghadapi ancaman bahaya erupsi, akan tetapi letusan gunungapi nampaknya sudah menjadi hal biasa dalam kosmologi jawa termasuk permohonan kepada Roh (penguasa) Merapi dalam ritual berdoa penganut Hindu-Buddha (Subandriyo, 2013: 4). Fasies gunungapi yang dijumpai di sekitar Candi Asu menunjukkan jejak-jejak erupsi Gunungapi Merapi pada masa lampau yang berdampak terhadap wilayah ini. Berdasarkan konsep dalam geomorfologi yang mengatakan bahwa the present is the key to the past, dapat diidentifikasi bahaya erupsi yang telah terjadi pada masa lampau yaitu berupa aliran piroklastik dan aliran lahar yang jejakjejaknya dijumpai pada lembah Sungai Pabelan, serta hujan abu dan kerikil (lapili).

Pada akhirnya letusan besar Merapi menyebabkan terganggunya tatanan kehidupan masyarakat. Letusan besar diperkirakan terjadi sekitar tahun 765 - 911 M (Andreastuti dkk, 2006: 7) serta 994-1168 M (Subandriyo, 2013: 5). Letusan-letusan besar ini memberikan dampak signifikan terhadap kehidupan. Berdasarkan kajian stratigrafi di sekitar candi, diketahui bahwa pada umumnya candi-candi di sekitar Merapi tertutup oleh endapan lahar bahan jatuhan (tefra). Candi Lumbung terkubur 6-7 meter oleh lapisan tefra, endapan awan panas, dan lahar. Endapan bawah terbentuk setelah tahun $650 \mathrm{M}$ sedangkan endapan atas setelah tahun 1500 M. Candi Pendem terkubur endapan setebal 3 meter dengan material bom vulkanik (Subandriyo, 2013: 5).

Walaupun belum ada keterangan yang menjelaskan secara pasti pengaruh erupsi Merapi terhadap berpindahnya pusat peradaban Hindu-Buddha dari Jawa Tengah ke Jawa Timur, beberapa letusan besar termasuk diantaranya yang mengubur candi-candi di kompleks Candi Asu diduga berperan sebagai salah satu faktor yang mendorong perpindahan tersebut. Kerajaan Mataram telah dipindahkan ke Jawa Timur pada tahun 928
M (Andreastuti dkk, 2006: 7), sementara di Jawa Tengah selama periode $928 \mathrm{M}$ hingga abad 15 hanya ditemukan satu peninggalan tulisan dan sistem pemerintahan masyarakat yang tersisa berubah dari terpusat menjadi pemerintah lokal (Fontein, 1990; De Casparis, 1950 dalam Subandriyo, 2013: 4-5).

Dampak erupsi berupa aliran lahar, awan panas, dan material jatuhan yang terjadi di masa lalu masih sangat mungkin terjadi pada masa yang akan datang. Hal ini tidak terlepas dari aktivitas Gunungapi Merapi yang masih terus aktif hingga saat ini. Konsep geomorfologi yang menyatakan bahwa "hukum dan proses fisis yang berlaku pada saat ini, berlangsung pula sepanjang waktu geologi waaupun intensitasnya tidak selalu sama dengan saat ini" (Thornbury, 1969: 16 ), juga mengisyaratkan bahwa peristiwa bencana pada masa lampau masih memiliki potensi untuk terulang kembali pada masa mendatang. Berkaitan dengan kondisi tersebut masyarakat yang saat ini menempati kawasan sekitar Candi Asu harus menyadari dan memahami ancaman bahaya erupsi Gunungapi Merapi. Belajar dari pengalaman pada masa lampau, risiko akibat bencana erupsi dapat dikurangi dengan melakukan tindakan pengelolaan kebencanaan yang baik diawali dari peningkatan kesadaran masyarakat mengenai bencana. Fasies gunungapi yang menunjukkan rekam jejak erupsi masa lampau dapat dimanfaatkan sebagai informasi dasar dalam pengelolaan kebencanaan, yaitu menunjukkan peristiwa erupsi yang pernah terjadi dan dampaknyaterhadap kehidupan pada masa lampau.

\section{SIMPULAN}

Kompleks Candi Asu yang dibangun pada kaki Gunungapi Merapi bagian barat berdasarkan analisis geomorfologi dan litofasies termasuk dalam fasies medial. Pada masa lalu wilayah ini pernah mengalami bencana akibat aliran lahar, awan panas, dan hujan abu. Candi pendem dan candi lumbung bahkan terkubur 3 hingga 7 oleh material vulkanik. Bukti-bukti letusan Merapi di masa lalu antara lain dijumpai pada lembah Sungai Pa- 
belan berupa endapan lahar dan prioklastik, serta endapan jatuhan yang mendominasi sebagian besar wilayah saat ini. Bukti-bukti letusan pada masa lampau yang dijumpai di sekitar Candi Asu diduga merupakan faktor yang menyebabkan kemunduran kehidupan masyarakat. Secara umum gangguan tatanan kehidupan masyarakatjuga disebabkan oleh beberapa periode letusan besar Gunungapi Merapi. Diduga kompleks Candi Asu mulai ditinggalkan masyarakat bersamaan dengan perpindahan pusat kekuasaan dari Jawa Tengah ke Jawa Timur. Pada saat sekarang wilayah tersebut kembali ditempati oleh penduduk sehingga menimbulkan risiko bencana pada masa mendatang. Risiko bencana semakin meningkat karena pertumbuhan penduduk cukup tinggi di wilayah ini. Dalam upaya mengurangi risiko bencana salah satu informasi yang dibutuhkan adalah potensi bahaya berdasarkan sejarah bencana masa lalu, yang diidentfikasi melalui kajian fasies gunungapi.

\section{UCAPAN TERIMA KASIH}

Terima kasih kepada semua pihak yang turut membantu proses penulisan artikel ini serta kepada redaktur yang memuat hasil artikel. Semoga dapat memberikan kontribusi bagi dunia pendidikan.

\section{DAFTAR PUSTAKA}

Andreastuti, S,D., Newhall, C., dan Dwiyanto, J. 2006. Menelusuri Kebenaran Letusan Gunung Merapi 1006. Jurnal Geologi Indonesia 1 (4): 201-207.

Bronto, S. 2006. Fasies Gunung Api dan Aplikasinya. Jurnal Geologi Indonesia 1 (2): 59-71.
Davidson, J., dan De Silva, S. 2010. Composite Vocanoes. dalam Encyclopedia of Vocanoes. Academic Press.

Degroot, V.M.Y. 2009. Candi Space and Landscape: A Study on the Distribution, Orientation, and Spatial Organization of Central Javanese Temple Remains. Disertasi. Universiteit Leiden. Diakses melalui www.openaccess.leidenuniv.nl. 9 Oktober 2013.

Kelman, I dan Mather, T.A. 2008. Living with Volcanoes: The Sustainable Livelihoods Approach for Volcano-related Opportunities. Journal of Volcanology and Geothermal Research 172: 189-198.

Marfai, M.A., Cahyadi, A., Hadmoko, D.S., dan Sekaranom, A.B. 2012. Sejarah Letusan Gunung Merapi Berdasarkan Fasies Gunungapi di Daerah Aliran Sungai Bedog, Daerah Istimewa Yogyakarta. Riset Geologi dan Pertambangan 22 (2): 73-79.

Santosa, L.W. 2006. Kajian Hidrogeomorfologi Mataair di Sebagian Lereng Barat Gunungapi Lawu. Forum Geografi20 (1): 68-85.

Subandriyo. 2011. Sejarah Erupsi Gunung Merapi dan Dampaknya Terhadap Kawasan Borobudur. diakses melalui www.konservasiborobudur.org tanggal 9 Oktober 2013.

Sutikno dkk 2007. Kerajaan Merapi Sumberdaya Alam dan Daya Dukungnya. Yogyakarta: BPFG UGM.

Thornbury, W.D. 1969. Principles of Geomorphology. New York: John Wiley and Sons. 